been made recently, so great as to encourage us to hope that the problem is soluble and even that a solution lies not far ahead.

Iron and Steel Institute: Awards

THE following awards have recently been made by the Iron and Steel Institute: Bessemer Medal, to H. H. Burton (English Steel Corporation, Ltd.), for his distinguished services to the steel industry and to metallurgy, with particular reference to the development of alloy steels and of heavy forgings; Sir Robert Hadfield Medal, to Dr. L. Reeve (ApplebyFrodingham Steel Co.), in recognition of his contributions to the science and practice of ferrous metallurgy and, in particular, his researches on the weldability of low-alloy steels; Williams Prize, jointly to J. A. Bond (Appleby-Frodingham Steel Co.) and T. Sanderson (Workington Iron and Steel Co.) for their paper on "Full-Scale Blast-Furnace Trials" (J. Iron and Steel Inst., 168, 24 ; 1951).

\section{International Seaweed Symposium at Edinburgh}

An international seaweed symposium, sponsored by the Institute of Seaweed Research, Inveresk, Midlothian, will be held in Edinburgh during July 14-17. Sessions will be held in the Department of Zoology, University of Edinburgh, and will deal with the following major topics: phycology; algal chemistry; harvesting technology; utilization in industry, medicine and agriculture; world seaweed. resources-survey and conservation. Papers will be about half an hour in duration and adequate time will be allowed for discussion. On July 13, the day before the opening, an excursion will be made to $\mathrm{St}$. Andrews and the Gatty Marine Laboratory. During the symposium there will be excursions to the Institute of Seaweed Research and to Dunbar, where mechanical harvesting techniques will be demonstrated. Accommodation can be reserved at the University of Edinburgh students' hostels. Further information can be obtained at the Institute of Seaweed Research from Mr. T. W. Summers, secretary to the organizing committee for the symposium. During July 10-12, immediately prior to the symposium, the recently formed group of British phycologists is holding its annual summer meeting in Edinburgh. There will be excursions and prepared demonstrations of recent techniques in phycological research, with special emphasis on cytology, anatomy and culture methods. Those taking part in the international seaweed symposium are invited to take part also in this other meeting.

"Effect of Vitamin A-Deficiency on the Dark Adaptation of the Pigeon"

Is the communication under this title published in Nature, March 8, p. 413, Mr. J. W. Waters inadvertently omitted the key to the graph. It should read: $0---0$, normal pigeon; $\square-\cdots \square$, normal pigeon ; $-\cdots, 17$ months deficient diet ; $\Delta \cdots \Delta$, 17 months deficient diet, followed by 1 month of 100 I.U. vit. A/gm. diet; $\triangle 17$ months deficient diet, followed by 4 months of 100 r.v. vit. A/gm. diet; - 17 months deficient diet, followed by 4 months of 100 r.J. vit. A/gm. diet, followed by 5 months normal mixed diet.

\section{Announcements}

Mr. JoHN ROGERS, chairman of Imperial Chemical Industries, Ltd., has been elected a member of the Athenæum under the provisions of Rule 2 of the
Club, which empowers the annual election by the Committee of a certain number of persons of distinguished eminence in science, literature or the arts, or for their public services.

Prof. RENÉ Garnier, professor of mathematics (analysis applied to geometry) in the Sorbonne, has been elected a member of the Geometry Section of the Paris Academy of Sciences in succession to the late Prof. E. Cartan.

Dr. A. Neuberger has been appointed chairman of the editorial board of the Biochemical Journal in succession to Dr. E. J. King, who is retiring. All communications regarding the Biochemical Journal should be addressed, after April 1, to Dr. Neuberger at the National Institute for Medical Research, The Ridgeway, Mill Hill, London, N.W.7.

Dr. B. K. BLount, director of scientific intelligence in the Ministry of Defence, has been appointed a deputy secretary in the Department of Scientific and Industrial Research. Dr. Blount's post is a scientific one, and he will be able to relieve the secretary of the Department, Sir Ben Lockspeiser, of some of the increasingly heav $\bar{y}$ burdens of that office.

The title of reader in applied mathematics in the University of London has been conferred on Dr. G. J. Whitrow in respect of the post held by him at the Imperial College of Science and Technology.

The Institute of Metals is offering two prizes of twenty guineas (10 guineas cash, and 10 guineas in books) for the best essays on each of the following subjects : non-ferrous foundry practice; and metallography in industry. The competition is restricted to persons less than twenty-five years of age who are student members of the Institute or are associate members of local sections and eligible for student membership. Essays, which must not exceed 3,500 words in length, should be sent to the Secretary, Institute of Metals, 4 Grosvenor Gardens, London, S.W.1, not later than May 19.

A course of twelve lectures on the "Fundamentals of Applied Photography", arranged jointly by the Imperial College of Science and Technology, the Royal Photographic Society and the Institute of British Photographers, will be given in the Physics Department of the Imperial College, South Kensington, London, S.W.7, on Tuesdays and Thursdays, at 4.30 p.m., commencing on April 29. The main purpose of the course is to provide instruction for those who wish to use photography in industry. The lectures will be accompanied by practical demonstrations, where appropriate, and will cover sensitometry, processing, spectral sensitivity, physical nature of the developed image, photographic photometry, latent-image theory, and applications to low-energy and high-energy quanta. The fee for the course is two guineas (free to students of the Imperial College). Further details can be obtained from the Registrar of the Imperial College.

THe ninth annual private exhibition of British components, valves and test gear for the radio, television, electronic and telecommunications industries, which is known as the "British Radio Component Show, 1952", will be held at Grosvenor House, Park Lane, London, W.1, during April 7-9. Further information can be obtained from the organizers of the exhibition-the Radio and Electronic Component Manufacturers Federation, 22 Surrey Street, Strand, London, W.C.2. 